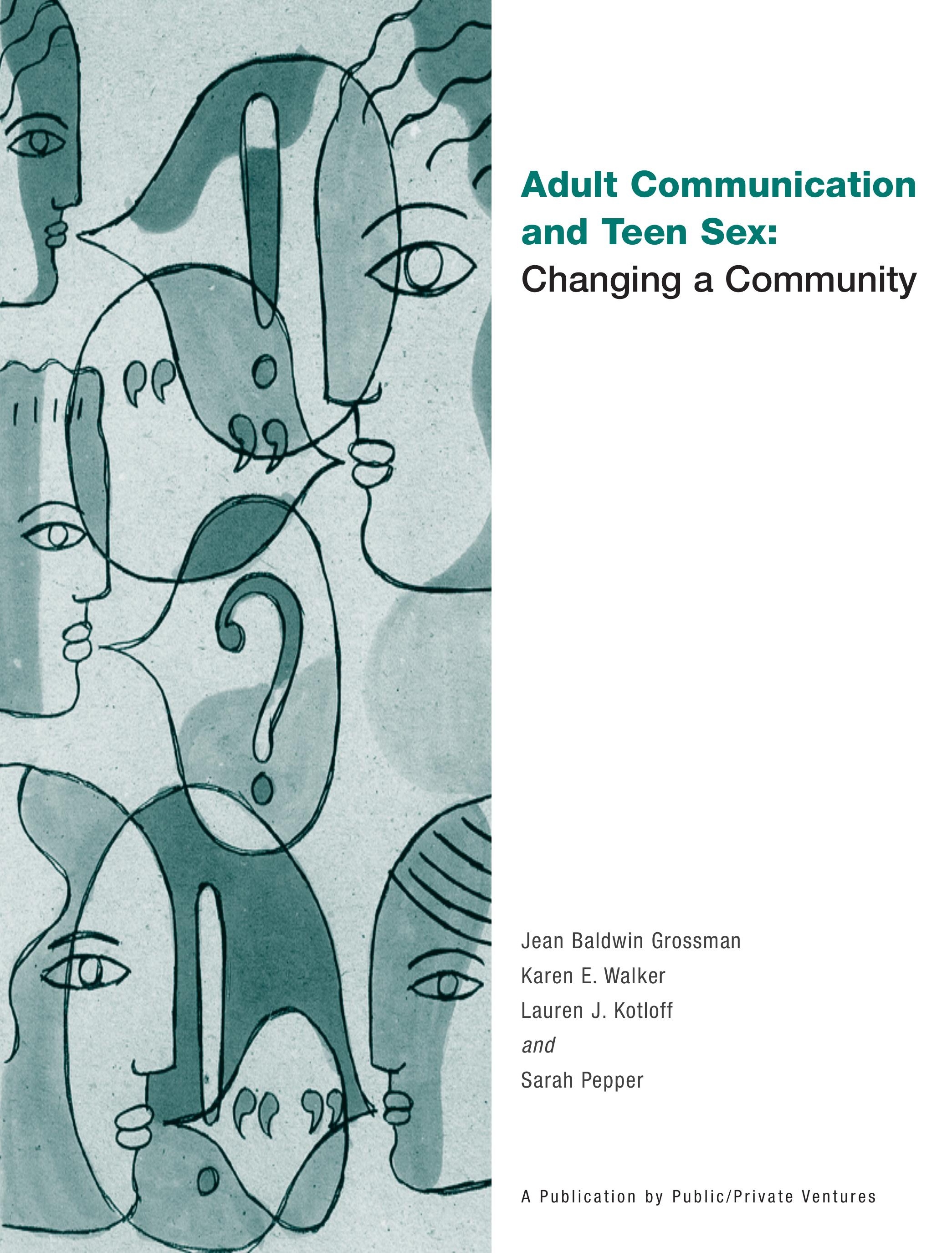




\section{Adult Communication and Teen Sex: Changing a Community}

Jean Baldwin Grossman

Karen E. Walker

Lauren J. Kotloff

and

Sarah Pepper 
Public/Private Ventures is a national nonprofit organization that seeks to improve the effectiveness of social policies and programs. $\mathrm{P} / \mathrm{PV}$ designs, tests and studies initiatives that increase supports, skills and opportunities of residents of low-income communities; works with policymakers to see that the lessons and evidence produced are reflected in policy; and provides training, technical assistance and learning opportunities to practitioners based on documented effective practices.

\section{Board of Directors}

Siobhan Nicolau, Chair President

Hispanic Policy Development Project

Gary Walker

President

Public/Private Ventures

Amalia Betanzos

President

Wildcat Service Corporation

Yvonne Chan Principal

Vaughn Learning Center

John J. DiIulio, Jr.

Fox Leadership Professor of Politics, Religion and Civil Society University of Pennsylvania

Mitchell S. Fromstein Chairman Emeritus Manpower Inc.

Susan Fuhrman

Dean, Graduate School of Education

University of Pennsylvania

Christine L. James-Brown

President

United Way of Southeastern Pennsylvania

John A. Mayer, Jr. Retired, Chief Financial Officer J.P. Morgan Eै Co.

Matthew McGuire Investment Officer Office of the New York State Comptroller

Maurice Lim Miller Director Family Independence Initiative

Jeremy Nowak Chief Executive Officer The Reinvestment Fund

Marion Pines Senior Fellow, Institute for Policy Studies Johns Hopkins University

Robert Putnam Peter and Isabel Malkin Professor of Public Policy Harvard University

Isabel Carter Stewart Executive Director Chicago Foundation for Women

Cay Stratton Director National Employment Panel, London, U.K.

William Julius Wilson Lewis P. and Linda L. Geyser University Professor

John F. Kennedy School of Government Harvard University
Research Advisory Committee

Jacquelynne S. Eccles Chair

University of Michigan

Ronald Ferguson Kennedy School of Government

Robinson Hollister Swarthmore College

Alan Krueger Princeton University

Katherine S. Newman Kennedy School of Government 


\section{Acknowledgments}

The Annie E. Casey Foundation originated the idea that became the Plain Talk initiative. The Foundation was the original funder for the program and engaged an independent organization, Public/Private Ventures $(\mathrm{P} / \mathrm{PV})$, to conduct research. We are especially grateful to Cindy Guy and Debra Delgado for the helpful guidance they have given over the many years of this project.

Many P/PV research staff, past and present, have contributed to the Plain Talk research. Mary Achatz designed and helped implement much of the work through the early years of the initiative. Michelle Gambone was instrumental in working with the communities and provided important insights and analysis in the early years of the study. Annick Barker, Danista Hunte and Julie Rainbow assisted in early data collection. Alicia Morales and Crystal Wyatt helped develop, code and maintain the qualitative database. Batia Trietsch prepared the survey data for analysis. Among the key researchers on the project were four ethnographers who worked with us in Atlanta, New Orleans, San Diego and Seattle: Gail Myers, Melanie Harrington, Judy Harper and Suzanne Tedesko.

This study would not have been possible without the cooperation of Plain Talk community youth and adults, as well as the agency staffs. We thank them for talking with us about their families, communities, institutions, and their experiences with Plain Talk. We particularly thank key Plain Talk staff in each site: Tom Slattery, Lisa Corbin Perry, Tammi Fleming, Petrice Sams-Abiodun, Annika Warren, Enid Matos-Toro, Cheryl Boykins and Jemea Smith, Marta Flores, Howard Martin, and Flora Parisky.
Their cooperation and assistance were instrumental to this study. They gave generously of their time despite demanding schedules. Their openness and candor provided us with invaluable insights into the challenges that underlie efforts to implement community-based efforts. They also provided valuable suggestions on reports.

We would like to thank our P/PV colleagues and a number of external reviewers for their input at various points throughout the project: Gary Walker, Linda Jucovy, Frank F. Furstenberg, Jr., Marta Tienda, Isabel Stewart, Betty King, Charles Bosk, Kristin Moore, Joy Dryfoos, Robert Blum and Sharon Milligan. We especially wish to thank Robert Blum and Kristin Moore for their thorough and thoughtful review of this publication. Natalie Jaffe edited the manuscript and Audrey Walmsley processed it for production. As always, Maxine Sherman provided invaluable assistance in ushering the document through the production process. We thank them for their support and assistance. 



\section{Contents}

Executive Summary i

The Problem and the Initiative's Response 1

The Demonstration Sites and Their Programs 3

The Effects of Plain Talk on Neighborhood Youth 7

The Neighborhood Youth 9

The Change in Adult Communication $\quad 10$

Increasing Access to and Awareness of Where to Get Birth Control 12

Other Changes in Youth Attitudes and Behaviors 13

$\begin{array}{ll}\text { Plain Talk's Implementation } & 17\end{array}$

Building a Message and Preparing the Core Group of Residents 17

Spreading the Plain Talk Word in the Community 18

Spreading the Plain Talk Word to Other Institutions 20

$\begin{array}{lr}\text { Conclusions } & 21\end{array}$

$\begin{array}{lr}\text { Afterword } & 23\end{array}$

$\begin{array}{lr}\text { Endnotes } & 25\end{array}$

$\begin{array}{lr}\text { References } & 27\end{array}$ 


\section{Executive Summary}

Despite recent improvements, the rate of pregnancy among American teens is almost twice that of English and four times that of French teenagers (Singh and Darroch, 2000). Thus, teen pregnancy remains a problem in the United States. Most prevention programs touch the teens directly-providing them with information, direction and/or access to contraception. Research is building that some of these programs are effective (Kirby, 2001). However, the staff at The Annie E. Casey Foundation decided to investigate a complementary approach that worked on broad community mores, family influence and social supports. They asked could an intervention be developed that would increase the amount and quality of communication that American adults provide youth regarding responsible sexual decision-making. Thus, the Plain Talk initiative was born.

Plain Talk's goals were:

- To create a consensus among parents and adults about the need to protect sexually active youth through encouraging early and consistent use of contraceptives;

- To provide parents and other community adults with the information and skills they need to communicate more effectively with teens about responsible sexual behavior; and

- To improve adolescent access to quality, ageappropriate and readily available reproductive health care, including contraception.

Plain Talk focused on the needs of sexually active youth out of the observation that it is the rates of adolescent pregnancy-and not sexual activity-that vary between the United States and Europe.

To test the usefulness of this strategy in diverse settings, Plain Talk was implemented in five low-income urban neighborhoods in Atlanta, Hartford, New Orleans, San Diego and Seattle between 1993 and 1998. While each neighborhood had large numbers of sexually active youth, high rates of teen pregnancy and a demonstrated readiness to confront these problems, they were ethnically quite different. The Atlanta and New Orleans communities were completely African American; San Diego's was predominately Latino; Hartford's was mixed Latino and African American; and Seattle was mixed Asian and Caucasian. Implementation research was conducted in all the sites. For resource reasons, however, youth interviews were collected only in San Diego, Atlanta and New Orleans. 
Changes in youth attitudes and behaviors were tracked through a neighborhood survey of 12 to 18 year olds, once in 1994 and again in 1998.

Three factors complicate our ability to truly isolate the effects of Plain Talk on youth using the basis of these surveys. First, the communities were subject to forces other than Plain Talk, such as school health education curriculum changes and welfare reform. Second, broad societal changes were in play reducing pregnancy rates. Third, the youth interviewed in 1994 were not the same 12 to 18 year olds interviewed in 1999. To determine what changes were linked to the initiative, rather than these other factors, we carefully traced the effects of Plain Talk's two major mechanisms, adult-youth communication, and increased knowledge of and access to reproductive health services, while to the extent possible controlling for these other factors.

Overall, we conclude that communication between a youth and a knowledgeable adult about sexuality, combined with an increase in access to contraceptives, is positively associated with teens' sexual knowledge and behavior, much as the theory behind Plain Talk posits. In 1994, 33 percent of the sexually experienced youth had been pregnant or got someone pregnant. Four years later, 27 percent of the new cohort of sexually experienced neighborhood teens had been or gotten someone pregnant. However, had there been no change in the amount or quality of communication over the four-year study period, the pregnancy rate among this new cohort of teens would have been 38 percent. Analysis of the survey data suggests that nearly all of the 11 percentage point decrease was due to the increased effectiveness of communication. In 1994, as Plain Talk was just beginning, youth who had talked to adults about sex were only slightly less likely to become pregnant (or cause a pregnancy) relative to teens who had not talked to adults. In 1998, talkers were significantly less likely to become pregnant (or cause a pregnancy) than non-talkers. Similarly, the new type of adult-youth communication improved youth's knowledge about where to find birth control, and reduced their likelihood of getting an STD or having a child. Thus, Plain Talk's ambitious strategy of changing community communication patterns, combined with improved access to contraceptives, appears to be a promising strategy for protecting adolescents.
How did the sites accomplish it? The first step was to bring the issues of adolescent sexuality to the attention of residents through a survey of the target neighborhood. The information from this survey, which described the problems of their children (high rates of adolescent sexual activity, pregnancy and disease; limited knowledge about sexuality; and the unavailability and inaccessibility of health services), had a profound effect on motivating people to participate in the initiative.

Next, staff and a core group of residents developed strategies to increase adults' knowledge about sexuality and/or to encourage more effective communication between adults and youth. The "Plain Talk message," advocating responsible sexual decision-making, was tailored to each neighborhood and was spread in two ways-formally through adult workshops in residents' homes or the Plain Talk office, and informally through a cadre of trained residents who came to be known as "askable adults" and "askable parents." Originally it was assumed that the core group of highly trained residents would co-facilitate workshops. The intensive training, however, proved to be a laborintensive undertaking that took far longer than expected-approximately 18 months. There was an enormous amount of information to be digested and attrition from the group was high. Only two sites stayed the course of creating resident educators, one site training five Promotoras (San Diego) and the other training 10 Walkers and Talkers (New Orleans).

However, despite the long preparation time, using resident educators to spread the message ultimately enhanced the sites' capacity to reach a large number of people in a relatively short time. New Orleans was able to reach 800 adult residents and San Diego 1,350 adults in one year, while the two sites relying on professionals, Seattle and Atlanta, reached 300 and 125 , respectively, over three years. Using residents offered several advantages. Residents had access to people who were unknown to staff. In communities that were suspicious of outsiders, residents proved invaluable in creating and nurturing the links between the initiative and the community. In addition, resident-led discussions were more direct and knowledge focused. Residents appeared to be more comfortable than were professionals in broaching the difficult aspects of teenage sex with other residents. And, as residents, they felt they had the responsibility and the right to challenge other community members with that message. Professional health educators, on the other hand, saw themselves 
as outsiders and felt less free to engage residents in discussion involving morals and so concentrated more on improving adult-youth communication.

Initially, the content of resident workshops varied across the sites. Two sites focused heavily on helping adults communicate with teens and two focused on increasing the residents' sexual knowledge. By the end of the initiative, however, all sites agreed that workshops needed both factual information about adolescent sexuality and its consequences, and training in adult-youth communication.

While the most intensive training produced only a small group of residents with the skills required for message dissemination in formal settings, most of the sites felt they had succeeded in producing a larger cadre of "askable adults" who could present information informally in the community, function effectively as outreach workers and recruit other residents to the initiative.

"Askable parents" and "askable adults" played complementary roles in helping youth make responsible decisions about their sexual behavior. Trained parents did appear more likely to speak to their children. But we found that parents had difficulty discussing sexuality, other than abstinence, once their children reached puberty. Their teenage children, too, indicated a reluctance to approach their parents with questions, preferring to talk to another trusted adult about sexual relationships. For these reasons, it appears that training should include both community adults who are parents as well as those who are not-in particular, adults who work or interact with youth. Trained residents spoke with the friends of their own children and with community youth they encountered in the course of the day. These adults tailored their advice to the youth's age and whether he or she was sexually active. Youth reported appreciating this advice.

Complementing Plain Talk's effort to change the pattern and effectiveness of adult-youth communication was an effort to improve adolescents' access to quality, age-appropriate reproductive health care, including contraception. When clinics did exist in the neighborhoods, their hours of operation sometimes conflicted with youth's school schedules. All sites had considerable success in bringing new health services to their communities by forging strategic relationships with health care providers and sometimes by successfully using residents to apply pressure on funders to support the services.

Plain Talk was like no other pregnancy prevention program tried before. It investigated whether one could create an environment in America where (1) adults in a teen's daily life-their parents, relatives and neighbors-would provide them with the information and encouragement to protect themselves sexually, and (2) teens would have easy access to contraceptives; and, if so, would sexually active teens act more responsibly-protecting themselves more, be less likely to get pregnant, and have fewer STDsthan if communication and access were more limited. The answer from this evaluation is, "yes," but creating this environment is much slower and more arduous than expected.

Changing a community's consensus on any topic is no small feat. But to get American adults to give teens the clear message, "safe sex or no sex," was particularly ambitious. Yet, we found that progress was made in settings that a priori would appear particularly difficult—communities with low levels of adult knowledge about sexuality, low educational levels in general, and populations with strong traditional values (Mexican immigrants and religious individuals). The fact that it takes a long time to fundamentally change societal norms should come as no surprise. For example, it took three decades for the antismoking campaigns to reduce the rate of smoking from 52 percent to 28 percent. Thus, while the Plain Talk approach clearly is heading in the right direction, more time and continued effort will be needed to effect large changes in teen sexuality. 


\section{The Problem and the Initiative's Response}

A greater proportion of teenage girls become pregnant in America than in any other developed country-almost 1 in 10 girls between the ages of 15 and19 (Singh and Darroch, 2000). Though that rate of sexual activity is the same in America and Europe, the U.S. teen pregnancy rate is almost twice that of England and four times that of France. America pays a price for these teen births through reduced levels of education, reduced lifetime tax payments and increased welfare payments. The children, too, pay a price in terms of poorer health, lower cognitive development and more behavioral problems (Kirby, 2001).

What could account for the difference? There is a growing view among experts that the pervasive cultural attitude of "safe sex or no sex" (Figueroa and Redus, 1998) may be critical. Europeans view sexuality as a normal part of growing up, and the culture conveys the message that if you are old enough to have sex, you are old enough to do so responsibly.

The idea that culture and community have a strong effect on adolescence behavior has been gaining currency among youth experts. Thus, in the 1990s, a generation of initiatives began whose goals were to fundamentally change entire communities. In this setting, The Annie E. Casey Foundation staff developed a unique community change approach to teen pregnancy and sexually transmitted disease prevention, called Plain Talk. The Plain Talk demonstration was set up to explore whether a cultural shift in sexual attitudes could be achieved in American communities, and whether, when combined with greater access to contraceptives, teen pregnancy and sexual transmitted disease (STD) rates would decline. The initiative's core strategies were:

- To change the message community adults provide sexually active adolescents by creating a consensus about protecting sexually active youth through encouraging early and consistent use of contraceptives;

- To provide parents and other community adults with the information and skills they need to communicate more effectively with teens about responsible sexual behavior; and

- To improve adolescents' access to quality, ageappropriate and readily available reproductive health care, including contraception. 
Plain Talk was controversial to some communities because it did not advocate abstinence, but rather concentrated on addressing the needs of sexually active youth. It was also unique in that one of its two core strategies targeted youth indirectly through adults, both as recipients of accurate information about the issue and disseminators of that information.

Plain Talk focused on community adults because it wanted to change the community's attitude toward teen sexuality. It assumed that adults should play a key role in shaping sexual behavior norms among adolescents. Yet to do so would be difficult, because American parents often lack the information and confidence to engage their children in frank and open discussions about sexual behavior, or they fear giving the wrong messages to their children about the appropriateness of sexual involvement during adolescence. Professionals who work with youth may be uncertain that their messages to teens will be supported by their communities. At the same time, youth avoid approaching adults with questions about sex out of fear of adult disapproval. As a result, they often turn to their peers for information about sexuality and contraceptives, and that information is often inaccurate. Thus, a primary objective of Plain Talk was to provide parents and other community adults with the information and skills they needed to communicate more effectively with teens about responsible sexual behavior.

Plain Talk's community approach was also unusual. Developing a wide consensus on any topic is difficult, but especially with a topic as sensitive as adolescent sexuality. Given the cultural diversity in the United States, Plain Talk planners believed that consensus around a topic as sensitive as adolescent sexuality could be achieved only if residents helped shape and direct the course of the initiative. Thus, Plain Talk required high levels of community ownership and control. The involvement of parents and other community adults, as well as staff from community agencies, was critical at every stage of the development and implementation of the initiative. In particular, through their role as disseminators of the Plain Talk message to others in the community, residents were seen as key agents of community change. Working in partnership with local agencies, Plain Talk also hoped to create long-term changes in institutional policy and practices in support of better contraceptive services for youth. Thus, while Plain Talk communities all had the same objectives, each community was expected to develop its own plans about how to implement the initiative on the basis of a thorough assessment of community attitudes and local service needs and resources.

Public/Private Ventures conducted an independent evaluation of the initiative between 1993 and $1998 .{ }^{1}$ We found that the Plain Talk framework enabled communities to change the way adults communicated with teens about sexuality. By the end of the third year, many community adults had been trained, more youth spoke with adults than at the start of Plain Talk, and this increased level of communication was associated with improvements in neighborhood youth's sexual knowledge, attitudes and behaviors. In particular, we found:

- Increased levels of communication between adults and sexually active youth, and

- Increased levels of youth awareness of where to get birth control.

Youth who talked with adults, in turn:

- Knew more about and were more comfortable with contraceptives,

- Used birth control more,

- Used reproductive health services more, and

- Were less likely to have an STD or a pregnancy than youth who did not talk to an adult about contraception or sexuality.

We found that the involvement of community members fundamentally affected the initiative. Sites that used residents as trainers delivered training with more explicit sexual information and ultimately trained more residents than did sites that used professional trainers, though it took a long time adequately to prepare residents to be trainers. Our research also highlighted the importance of nonrelated adults as key advisors to whom teens turn for guidance when making critical life choices.

This report, provides information on how these results were obtained. We first briefly describe the demonstration communities and the programs put in place there. We then discuss in more detail the initiative's effects. The final section discusses the challenges encountered in implementing the initiative's design. 


\section{The Demonstration Sites and Their Programs}

To test the usefulness of this strategy in diverse settings, the Plain Talk planning process began in five low-income urban neighborhoods in Atlanta, Hartford, New Orleans, San Diego and Seattle. While each neighborhood had large numbers of sexually active youth, high rates of teen pregnancy and a demonstrated readiness to confront these problems, they were ethnically quite different. The Atlanta and New Orleans communities were completely African American; San Diego's was predominately Latino; Hartford's was mixed Latino and African American; and Seattle was mixed Asian and Caucasian. As shown in Table 1, rates of sexual activity among the communities varied widely. ${ }^{2}$

Sites also varied in their levels of informal and formal social organization. For example, strong informal networks existed among residents in the San Diego site, which includes a number of small businesses and other institutions. The Atlanta neighborhood, in contrast, had very few institutions and networks among the residents appeared to be fairly sparse. The New Orleans neighborhood had a high level of formal organization through the public housing unit's Resident Council. That formal organization, coupled with the relative stability of the local population over a number of years, supported the maintenance of dense networks that facilitated the work of Plain Talk. In every site, differences within and across the neighborhoods influenced the paths taken in Plain Talk's implementation. Strong networks, both formal and informal, facilitated Plain Talk; weak or sparse networks impeded its progress. Ethnic diversity complicated implementation activities, and cultural differences influenced the ways that staff framed Plain Talk. 
Table 1

The Plain Talk Communities

\begin{tabular}{|c|c|c|c|c|c|c|c|}
\hline \multirow[b]{2}{*}{ Site } & \multirow[b]{2}{*}{$\begin{array}{l}\text { Living below } \\
\text { Poverty Line* }\end{array}$} & \multirow[b]{2}{*}{ Ethnicity } & \multirow{2}{*}{$\begin{array}{l}\text { Average } \\
\text { Household } \\
\text { Size }\end{array}$} & \multicolumn{3}{|c|}{ Rates of sexual activity** } & \multirow{2}{*}{$\begin{array}{l}\text { Percent of } \\
\text { Sexually Active } \\
\text { Girls Ever } \\
\text { Pregnant }^{\star \star}\end{array}$} \\
\hline & & & & $\begin{array}{l}12-13 \\
\text { Yrs }\end{array}$ & $\begin{array}{l}14-15 \\
\text { Yrs }\end{array}$ & $\begin{array}{l}16-18 \\
\text { Yrs }\end{array}$ & \\
\hline Atlanta & $70 \%$ & African American & 4.3 & $17 \%$ & $49 \%$ & $82 \%$ & $62 \%$ \\
\hline Hartford & $70 \%$ & $\begin{array}{l}\text { African American } \\
\text { and Latino }\end{array}$ & N/A & N/A & N/A & N/A & N/A \\
\hline New Orleans & $86 \%$ & African American & 4.4 & $9 \%$ & $37 \%$ & $75 \%$ & $43 \%$ \\
\hline San Diego & $44 \%$ & Latino & 5.6 & $7 \%$ & $16 \%$ & $51 \%$ & $55 \%$ \\
\hline Seattle & $50 \%$ & Asian and White & N/A & N/A & N/A & $\mathrm{N} / \mathrm{A}$ & N/A \\
\hline
\end{tabular}

* Figures for Atlanta, Hartford, Indianapolis, New Orleans and San Diego are from the 1990 Census. Figures for Seattle are based on the site's estimate.

** Figures are from the baseline survey P/PV conducted in 1994 in Atlanta, New Orleans and San Diego. The "ever pregnant" numbers include girls who have had abortions or miscarriages.

Each program recruited a core group of residents charged with crafting the Plain Talk message about the needs of sexually active youth in a manner appropriate for their community, and developing an education program to increase the amount of communication between adults and youth about sexuality. In addition, sites were asked to work to increase the availability of reproductive health services and contraceptive access for neighborhood teens.

\section{Table 2}

The Plain Talk Programs as of 1997

$\begin{array}{ll}\text { Type of Adults } & \text { Workshop } \\ \text { Targeted } & \text { Focus }\end{array}$

communication

professionals

new clinic

5-10

Hartford

all adults

health concerns

professionals

new clinic

3-6

and communication

$\begin{array}{llllll}\text { New Orleans } & \text { all adults } & \text { knowledge } & \text { residents } & \text { broaden services } \\ \text { San Diego } & \begin{array}{l}\text { relatives and } \\ \text { other adults }\end{array} & \text { knowledge } & \begin{array}{l}\text { residents and } \\ \text { professionals }\end{array} & \text { increased hours } \\ \text { Seattle } & \text { parents } & \text { communication } & \text { professionals } & \text { new clinic (1998) }\end{array}$

Note: This table summarizes key aspects of the program that each site operated as of 1997-1998. It describes the adults targeted, the focus of the workshops (improving communication skills or improving participants' knowledge of human sexuality and protection), who ran the workshops, what new adolescent health services were implemented, and how many more teens used the clinics. Since 1998, most workshops cover both communication skills and information about sexuality. 
Like the target communities, the programs they developed were also different. Each site took a different approach to training adults—-targeting different adults and stressing different facets of the Plain Talk message, depending on local conditions and attitudes. The Atlanta and Seattle programs targeted parents of adolescents and ran a series of workshops that focused primarily on communication skills. The workshops in New Orleans and San Diego, on the other hand, targeted a broader audience and emphasized specific knowledge about sexuality and contraceptive use. In addition, in both sites, core group residents interacted informally with other adults and directly with youth. Between 1996 and mid-1997, five women became Promotoras (lay health educators) in San Diego, while New Orleans maintained a cadre of 10 "Walkers and Talkers" throughout 1997. Hartford offered a 12week workshop on teen pregnancy-prevention and parent-child communication, but discontinued it after the first one because of attendance problems. Instead they ran biweekly "health concerns" group sessions that covered a range of health and welfare concerns. We do not have data on the extent to which pregnancy prevention information was included.

Because sites' strategies differed, so did their dissemination rates by the end of their three-year foundation-funded implementation phase. Table 3 shows how many adults attended the workshops in each community.

\section{Table 3}

The Percentage of Neighborhood Adults Who Were Trained

\begin{tabular}{lccc} 
Site & $\begin{array}{l}\text { Population } \\
\text { Over 20+ }\end{array}$ & $\begin{array}{l}\text { Number of } \\
\text { Attendees at } \\
\text { Workshops }\end{array}$ & $\begin{array}{l}\text { Estimated } \\
\text { Dissemination } \\
\text { Rate }\end{array}$ \\
\hline Atlanta & 1,860 & 125 & $6.7 \%$ \\
Hartford & N/A & N/A & N/A \\
San Diego & 7,830 & 1,350 & $17.2 \%$ \\
New Orleans & 1,290 & 800 & $62.0 \%$ \\
Seattle & 6,570 & 300 & $4.6 \%$
\end{tabular}

N/A means not available.
Each site used different strategies to increase and improve adolescent reproductive health services. In Atlanta, Plain Talk staff teamed up with the local health department to bring a clinic to the neighborhood for the first time. In New Orleans, Plain Talk staff worked with the existing community health clinic to serve St. Thomas youth more comprehensively, and received funding from the State Department of Family Planning to open an adolescent clinic in the evening. In San Diego, the lead agency that operated its own reproductive health clinic substantially increased its service hours over the course of the initiative. In Seattle, Plain Talk staff worked with other agencies and residents to start a school-linked clinic (although it did not open until 1998).

In sum, by the end of the three-year implementation grant, each site had tailored the initiative to resonate with its community, while enabling and motivating community adults to talk more plainly to adolescents about sexuality. All had community education programs and had increased the availability of adolescent reproductive health services. In the next section, we examine what effects these changes had. 


\section{The Effects of Plain Talk on Neighborhood Youth}

Evaluating the effects of a community initiative is difficult for a number of reasons. Community initiatives attempt to change the behavior of an entire community. Thus, in order to ascertain whether Plain Talk caused the observed community changes, one would ideally compare the behavior in Plain Talk communities with the behavior in comparable communities without Plain Talk. Unfortunately, it was very difficult to find pairs of communities that remain comparable over a 5- to 10-year period-the time framework of most serious community initiatives. At the beginning of the study, we attempted to find comparison neighborhoods, but found none that were similar enough. As an alternative evaluation strategy, we decided to track the changes in attitudes and behaviors of 12- to 18-year-old neighborhood youth in Atlanta, New Orleans and San Diego through a pair of surveys-one in 1994 at the beginning of the initiative and another one in 1998 at the end. ${ }^{3}$

There were three factors that complicated our ability to isolate the effects of Plain Talk on the basis of these surveys. First, although Plain Talk was an important feature in these neighborhoods, the communities were subject as well to other forces that could affect teens' sexual behavior-such as school health education curriculum changes, state initiatives, national ad campaigns and national welfare reform changes. This was particularly true in Atlanta, where a state initiative was concurrently operating. Georgia Campaign for Adolescent Pregnancy Prevention (GCAPP) focused on the same neighborhood as Plain Talk and was designed to prevent pregnancy through a public campaign, as well as by providing youth development opportunities to adolescents.

Second, broad social changes relevant to the initiative occurred during the study period. For example, during the 1990s, rates of teen pregnancy fell around the country. Between 1994 and 1998, pregnancy rates for all girls ages 15 to 19 dropped 8.5 percent to 97 per 1,000 (Henshaw, 1999). Among black girls ages 15 to 19 , the pregnancy rate dropped 11.5 percent to 153 per 1,000. Data for the comparable time period are not available for Latino women, but from 1992 to 1996 their pregnancy rate dropped 6.3 percent to 165 per 1,000 . In addition, public education efforts aimed at preventing AIDS emphasized the danger of unprotected sexual activity and encouraged the use of condoms. ${ }^{4}$ 
Lastly, the 12- to 18-year-old youth interviewed in 1994 were not the same 12- to 18-year-old individuals interviewed in 1998. Most of the originally interviewed youth had aged out of the target group. Thus, some of the observed changes in attitudes and behaviors could be attributable to differences in the youth interviewed.

To better determine what community changes were linked to the initiative rather than these other factors, we carefully traced Plain Talk's hypothesized pathways, step by step. Plain Talk's theory of change is that:

1. Educating community adults should lead adults to speak to more youth and/or communicate more effectively about the need to practice safe and wise reproductive health practices. Thus, we first examined if more communication was taking place, then how communication was associated with teens' sexual attitudes and behaviors.

2. Plain Talk staff efforts should make both adolescent health services and birth control methods more available and user-friendly to adolescents. Thus, we examined first if youth were more aware of where to get condoms and services, then how increased awareness of birth control and protection were associated with their beliefs and actions.

\section{Figure 1}

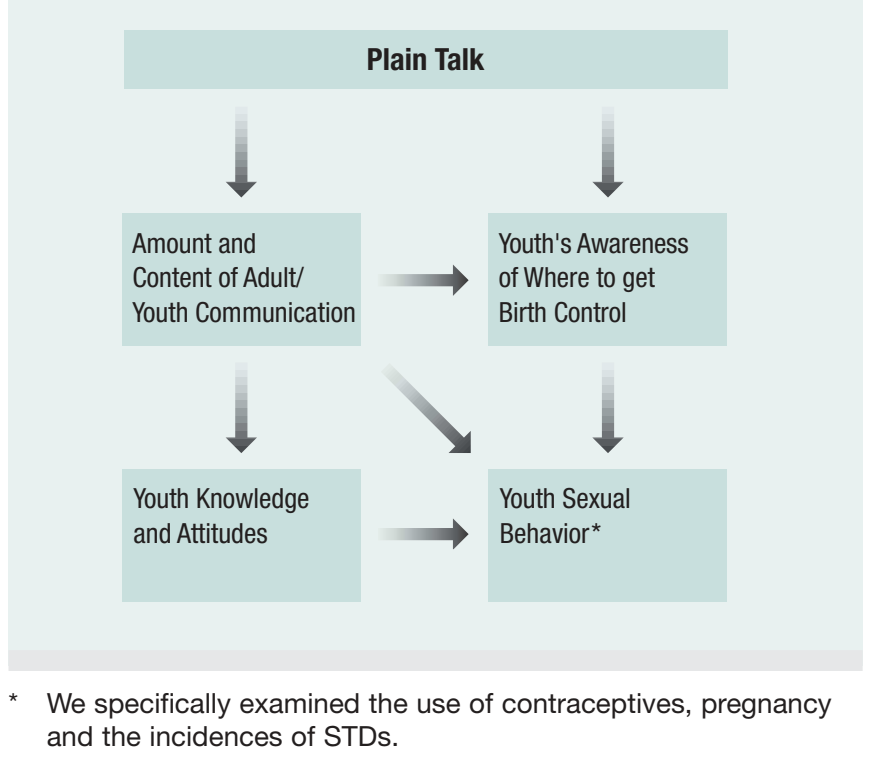

Figure 1 illustrates the pathways through which Plain Talk is expected to affect youth. The initiative directly aimed to change the nature of communication between neighborhood adults and youth, and the accessibility of birth control. All of the other desired outcomes (improved knowledge and attitudes, more responsible sexual behavior and fewer unwanted outcomes) should be affected in turn through the changes in communication and birth control accessibility.

In addition to taking this pathway approach to evaluating the initiative, we also attempted to control statistically for non-Plain Talk factors. We adjusted for changes due to the changing composition of the neighborhood youth and we controlled for broader site-level changes that could affect teen's behaviors.

The discussion that follows presents what changes we found step by step. In the first section, we describe the characteristics of the youth we interviewed. The second and third sections explore how the patterns of communication and youth's awareness of where to find birth control changed over the evaluation period. The fourth section explores how these two factors interacted with other key elements of teen sexuality. Specifically, we considered adolescent knowledge of birth control and attitudes toward their use, the use of contraceptives, pregnancy, and being tested and treated for an STD. 


\section{The Neighborhood Youth}

Table 4 shows the characteristics of youth interviewed in each wave. As we noted, the three sites differed dramatically with respect to race, but they also differed by immigrant status and religion. In San Diego, 44 percent of the youth were not born in the United States and 63 percent reported that they were Catholic. In New Orleans, 80 percent of the youth said they were Baptist; while Atlanta's youth were religiously more diverse. A third of Atlanta's youth declared they had no religion, while half viewed themselves as Baptists.
The profiles of the neighborhood youth remained similar over the two years with respect to age, gender and race. Approximately half the interviewed youth were girls. Approximately 30 percent of the interviewed youth were 12 or 13 years old, 40 percent were 14 to 16 , and 30 percent were 17 or 18 . About 60 percent of the youth were African American and 40 percent were Latino.

The primary change over time was in religious observance. In 1998, adolescents reported attending religious services less frequently than they had four year

\section{Table 4}

Characteristics of Interviewed Youth

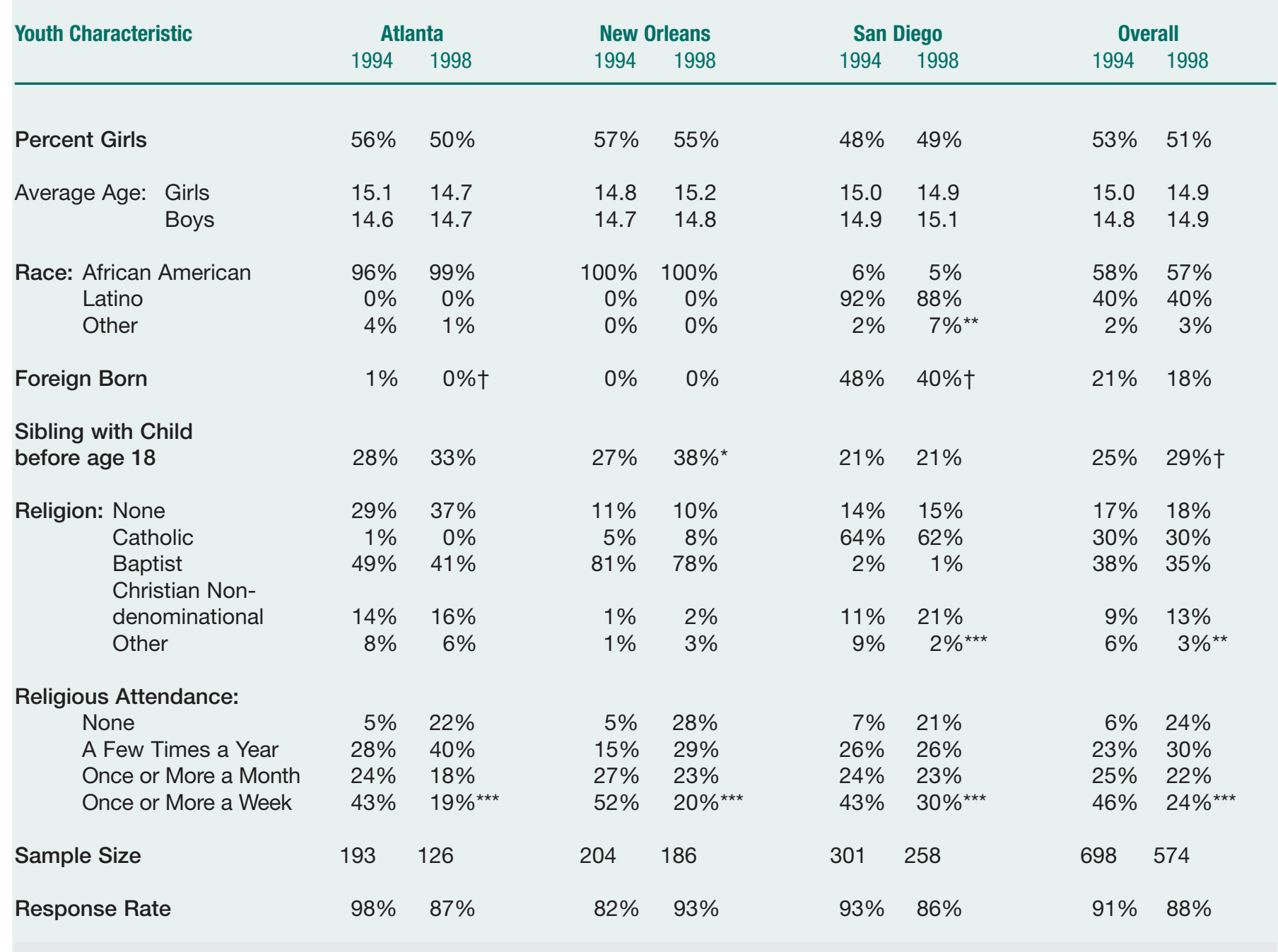

Note: We tested if characteristics differed between 1994 and 1998. If there were a statistically significant change, it was noted in the 1998 column. The level of significance is noted as follows:

$\dagger \mathrm{p} \leq .10 \quad$ ** $\mathrm{p} \leq .01 \quad$ *** $\mathrm{p} \leq .001$ 
earlier. While only 6 percent of the youth in 1994 said they never went to services, almost a quarter (24\%) reported this in 1998. Similarly, in 1994, almost half said they went to services at least once a week, while in 1998 only a quarter reported this frequency. A smaller, yet still significant, difference was that in 1998 more youth who considered themselves nondenominational Christian (13\% versus 9\%) and fewer said they were Baptists (35\% versus $38 \%$ ). The changing religious nature of the neighborhoods across the four years highlights the importance of controlling for these shifts when investigating the effects of Plain Talk.

\section{The Change in Adult Communication}

Did more youth in the Plain Talk communities speak with adults about sexuality in 1998 than in 1994? We asked youth whether they had discussed any of three topics with an adult-birth control, pregnancy and STDs-within the last year. Comparing the results of the two surveys (Table 5), we found there was more communication among sexually experienced youth. In 1998, 70 percent had talked to an adult within the last year, compared with 61 percent in 1994. In San Diego, the percentage went from 65 percent in 1994 to 77 percent in 1998. Similarly, in New Orleans, the percent of the sexually experienced youth that had spoken to adults increased from 58 percent to 65 percent. In Altanta, it appeared there was an increase for both sexually experienced and the sexually inexperienced youth, although the increase was larger for inexperienced youth.

The types of adults who talked to youth in 1998 were consistent with the dissemination strategy chosen by the sites. In New Orleans the Plain Talk message was directed toward all adults. Youth in that site also were encouraged to talk with "Walkers and Talkers," trained resident adults. Table 6 shows the largest increase in communication among in sexually active youth who talked with unrelated adults. In 1994, 30 percent of sexually active New Orleans youth spoke with unrelated adults about birth control, pregnancy or STDs; in 1998, 45 percent did so. Also of the three sites, New Orleans put the largest emphasis on involving men in Plain Talk by creating a separate group called Black Men United for Change. The group's leaders made a point to mentor young males and speak to them about responsibility and sexuality, especially about not fathering children before they were ready to be a parent. Although not shown in the table, we observed a significant increase in the number of boys who had talked to an unrelated male (25 percent of all boys in 1998 compared with 14 percent in 1994; among the sexually experienced boys, the increase was from 30 percent to 45 percent).

Atlanta emphasized training parents, but relatively few were trained. Therefore, no significant findings were seen among sexually experienced youth. We do not know why there was an increase in communication between sexually inexperienced youth and unrelated adults. It could be related to a change in the schools, but the major change in the schools, the introduction citywide of "Postponing Sexual Involvement," a health education class for all fifth graders, did not occur until after the study period.

In San Diego, the Plain Talk message was aimed at all adults. However, because dense family networks existed in that neighborhood, the nonparental adults the youth interact with were primarily relatives-aunts, uncles and cousins. Although the observed changes are very much in line with the theory of Plain Talk, it is important to remember that inducing shifts in communications patterns between adults (especially unrelated adults) and youth around sexuality is likely to be a very long-term endeavor. Even in New Orleans, where a majority of the adults had attended a workshop and there was a strong emphasis on involving men (who would feel the most comfortable speaking with boys), change was modest. 
Table 5

Percentage of Youth Who Talked with an Adult in the Previous Year About Topics Related to Pregnancy, STDs or Birth Control

\begin{tabular}{lcccccccc} 
& \multicolumn{2}{c}{ Atlanta } & \multicolumn{2}{c}{ New Orleans } & \multicolumn{2}{c}{ San Diego } & \multicolumn{2}{c}{ Overall } \\
& 1994 & 1998 & 1994 & 1998 & 1994 & 1998 & 1994 & 1998 \\
\hline Overall & $56 \%$ & $68 \%$ & $53 \%$ & $55 \%$ & $61 \%$ & $59 \%$ & $57 \%$ & $60 \%$ \\
Sexually Experienced: & $60 \%$ & $69 \%$ & $58 \%$ & $65 \%$ & $65 \%$ & $77 \%$ & $61 \%$ & $70 \%^{*}$ \\
Sexually Inexperienced: & $51 \%$ & $68 \%^{*}$ & $50 \%$ & $45 \%$ & $59 \%$ & $51 \%$ & $55 \%$ & $53 \%$ \\
Sample Size & 193 & 126 & 204 & 186 & 301 & 258 & 698 & 570
\end{tabular}

Note: The table consists of simple frequencies from the surveys. We tested whether 1998 values were equal to the 1994 values.

The level of significance is noted as follows:

* $\mathrm{p} \leq .05$

\section{Table 6}

Percentage of Youth Who Talked About Any Sexuality Related Topic to Each Type of Adult

\begin{tabular}{|c|c|c|c|}
\hline Atlanta & New Orleans & San Diego & Overall \\
\hline 19941998 & 1994 & $1994 \quad 1998$ & 1994 \\
\hline
\end{tabular}

\section{Sexually Experienced:}

Female Relative

Male Relative

Other Adult

Sexually Inexperienced:

Female Relative

Male Relative

Other Adult

$\begin{array}{ll}48 \% & 57 \% \\ 19 \% & 25 \% \\ 35 \% & 40 \%\end{array}$

$40 \% 56 \%$ *

$6 \% \quad 13 \% \dagger$

$30 \% 45 \%$ *

$\begin{array}{ll}26 \% & 51 \% \text { *** } \\ 19 \% & 32 \% \dagger \\ 49 \% & 54 \%\end{array}$

$38 \% 55 \%$ ***

$15 \%$ 23\%*

$35 \% \quad 40 \%$

$\begin{array}{ll}36 \% & 47 \% \\ 17 \% & 15 \% \\ 28 \% & 42 \% \dagger\end{array}$

$\begin{array}{rr}43 \% & 35 \% \\ 5 \% & 8 \% \\ 17 \% & 18 \%\end{array}$

$\begin{array}{ll}34 \% & 41 \% \\ 12 \% & 21 \% * \\ 41 \% & 31 \% \dagger\end{array}$

$37 \% \quad 41 \%$

$11 \% \quad 16 \%$ *

$31 \% \quad 30 \%$

Note: The table consists of simple frequencies from the surveys. We tested whether 1998 values were equal to the 1994 values. The level of significance is noted as follows:

$\dagger \mathrm{p} \leq .10 * \mathrm{p} \leq .05 \quad * * * \mathrm{p} \leq .001$ 


\section{Increasing Access to and Awareness of Where to Get Birth Control}

\begin{tabular}{|c|c|c|c|c|c|c|}
\hline \multirow{2}{*}{ Population } & \multicolumn{2}{|c|}{ Atlanta } & \multicolumn{2}{|c|}{ New Orleans } & \multicolumn{2}{|c|}{ San Diego } \\
\hline & 1994 & 1998 & 1994 & 1998 & 1994 & 1998 \\
\hline Overall & $80 \%$ & $70 \% \dagger$ & $69 \%$ & $75 \%$ & $50 \%$ & $60 \% *$ \\
\hline Girls & $81 \%$ & $80 \%$ & $70 \%$ & $87 \%$ ** & $52 \%$ & $60 \%$ \\
\hline Boys & $79 \%$ & $61 \% *$ & $66 \%$ & $61 \%$ & $47 \%$ & $59 \% *$ \\
\hline $\begin{aligned} & \text { Note: } \text { The } \\
& 1998 \\
& \text { signi } \\
& \dagger \mathrm{p}\end{aligned}$ & $\begin{array}{l}\text { ble con } \\
\text { alues } \mathrm{u} \\
\text { cance is } \\
0\end{array}$ & $\begin{array}{l}\text { sts of sin } \\
\text { re equal } \\
\text { noted as } \\
p \leq .05\end{array}$ & $\begin{array}{l}\text { le freque } \\
\text { the } 199 \\
\text { llows: } \\
\star \star \quad p \leq .\end{array}$ & $\begin{array}{l}\text { encies. } W \\
4 \text { values. } \\
01\end{array}$ & $\begin{array}{l}\text { tested } \\
\text { ne level }\end{array}$ & $\begin{array}{l}\text { hether } \\
\text { of }\end{array}$ \\
\hline
\end{tabular}

All sites improved adolescent reproductive health services and increased assess to birth control. Clinics increased their hours, made them compatible with school schedules and became more aware of practices that encourage adolescents to use health care services. But for these services to be used, youth must know about them.

Did more youth know where to get birth control in 1998 than in 1994? We found that youth's awareness increased in San Diego and New Orleans. ${ }^{5}$ The proportion of youth knowing where to get contraceptives increased in San Diego from 50 percent to 60 percent and from 69 percent to 75 percent in New Orleans. In New Orleans, the increase in girls' knowledge was particularly large, going from 70 percent to 87 percent. In Atlanta, knowledge of where to get birth control did not increase between 1994 and 1998; and among boys, knowledge decreased from 79 percent in 1994 to 61 percent in 1998. Although the downturn in Atlanta is disheartening, an increase was not expected since the adult education classes had not reached large numbers of individuals. Overall, the rates by gender underscores the difficulties in reaching out to teen boys.

Deeper investigation helped us understand what led to these changes. We found that, in both 1994 and 1998, youth who had talked with adults in the previous year about birth control were more likely to know where to find it. The first line of Table 8 indicates that in 1994 youth who had talked with an adult were 1.4 times more likely to know where to find birth control than were their peers who had not had such conversations. In 1998, youth who had talked with an adult were over twice (2.1 times) as likely to know a source for birth control than were similar nontalking peers. ${ }^{6}$

\section{Table 8}

Logit Analysis of Youth's Awareness of Where

to Get Birth Control

\section{Contributing}

Factor Odds Ratio

Communication:

1994 Talk

$1.4 \dagger$

1998 Talk

$2.1^{\star \star *}$

City Trends:

Atlanta 1998 $.58 \dagger$

New Orleans 1998

1.35

San Diego 1998

1.36

Note: Details of the analysis are described in endnote 6.

$\dagger \mathrm{p} \leq .10$

*** $\mathrm{p} \leq .001$

Plain Talk informed youth where to find birth control not only by encouraging adults to talk to them but by having staff talk directly with them too. New Orleans and San Diego both held youth-oriented events. New Orleans held many Protection Pizza Parties, at which information about condoms was disseminated and condoms distributed to youth. In San Diego, the Plain Talk health educator regularly gave workshops at local schools to youth who were involved in the Latino Advocacy program, a school-based program designed to give Latino youth support to stay in school. At these events, facilitators and trainers provided information to the teens about where to find birth control and reproductive health services. In addition, in 1996, a male peer education program, Smart Teens Educating Peers, was implemented by the Plain Talk staff. Adolescent males who participated 
were trained in ways similar to the Promotoras and attended large group events. For example, staff gave a talk about manhood and sexual responsibility to more than 300 male high school students. In 1997, San Diego expanded its peer education program to girls. Atlanta sponsored a youth leadership workshop during two summers in which responsible sexual decision-making was discussed, but this did not provide information on local sources of birth control.

The bottom half of Table 8 shows how youth's awareness in 1998 differed from that in 1994, after accounting for the positive effect of communication. In Atlanta, youth in 1998 were only 58 percent as likely as similar youth in 1994 to know where to get birth control. We speculate that the decrease from 1994 to 1998 could have been due to the population shift that occurred over these years. Between 1994 and 1998, many residents moved out of the increasingly poor community, perhaps leaving behind a population with fewer social resources and sparser informational networks. In San Diego and New Orleans, there were no significant gains in awareness attributable to general shifts.

\section{Other Changes in Youth Attitudes and Behaviors}

The previous section indicates that during the period of the Plain Talk initiative the amount of communication about sexuality between adults and sexually experienced youth increased. Youth who talked with adults were also more likely to know where to get birth control. Both of these changes were explicitly targeted by the initiative. In this section, we examine whether these two factors were related to teen's knowledge, attitudes and behavior as specified in the program's theory of change.

Figure 2 shows what patterns we found in $1998 .^{7}$ Compared to similar youth who did not talk to adults, youth who did talk with adults in 1998:

- Had more accurate knowledge about birth control (answering approximately one more true/ false question correctly on a 15-question quiz), and

- Felt more comfortable about condoms and birth control in general.

\section{Figure 2}

Pathways of Plain Talk

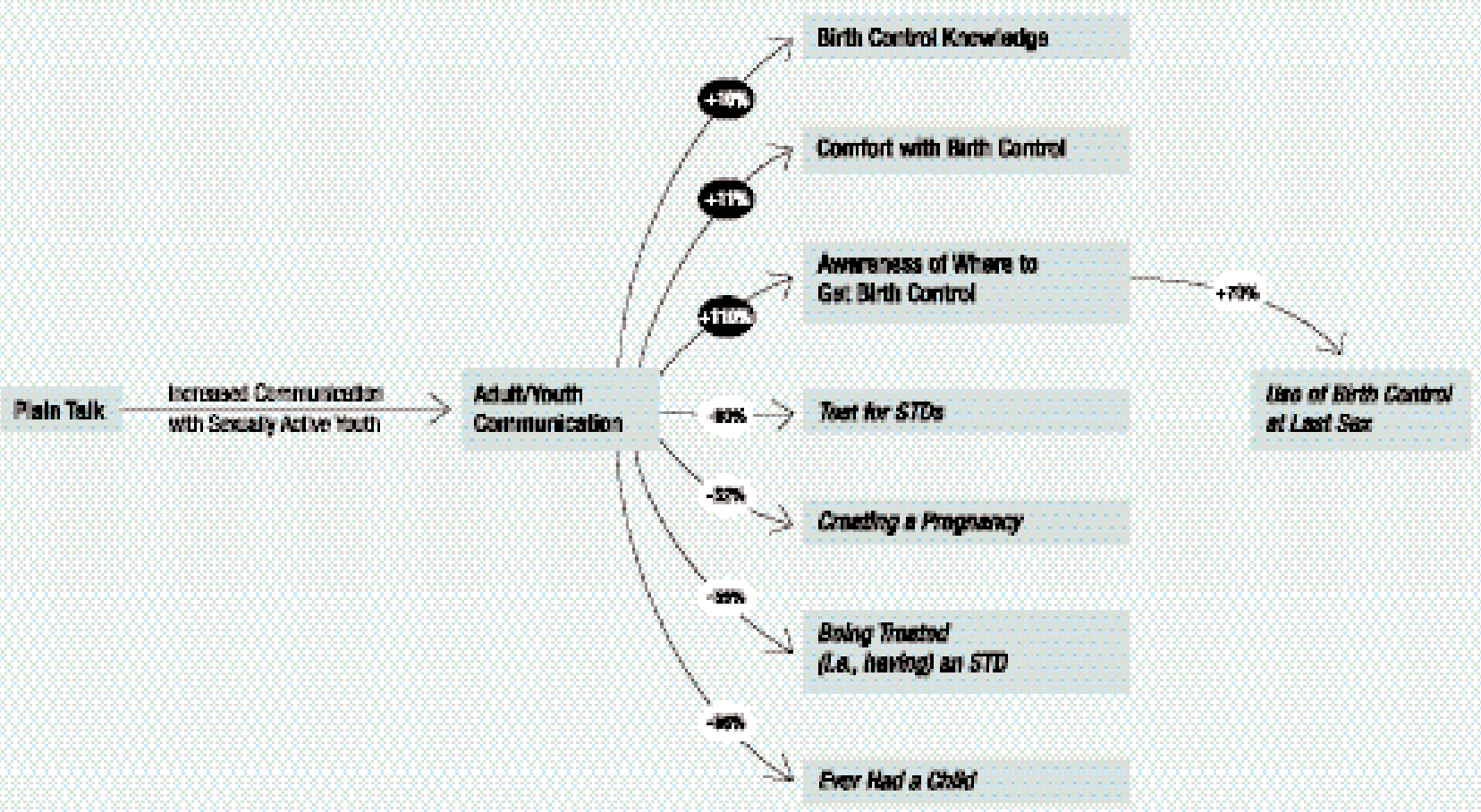

Note: This figure summarizes the results of multivariate analyses. Details of the analyses are described in endnote 7 . The impact estimates in the white circles were estimated for sexually experienced youth only. All estimated effects are significant at at least a 10 percent level of significance. 
Among sexually experienced youth, those who had talked with an adult:

- Were 80 percent more likely to get tested for STDs (a proxy for having a routine reproductive health check-up),

- Were half as likely to be treated for (i.e., have) an STD,

- Were half as likely to have had or have created a pregnancy (the girls were 70 percent less likely to get pregnant), and

- Were half as likely to have had a child.

The relationship between communication and youth's use of birth control was indirect. Youth who spoke with an adult in 1998 ("talkers") were twice as likely to know where to find birth control. In turn, youth who knew where to find birth control were 70 percent more likely to have used a contraceptive the last time they had sex.

For many outcomes, the relationship between talking and improved adolescent behavior was stronger in 1998 than in 1994-as one might expect if Plain Talk were working. Adult/youth communication was more strongly related in 1998 than in 1994 to:

- Knowing where to find birth control,

- Reducing the likelihood of getting an STD,

- Reducing the likelihood of getting pregnancy or fathering a child, and

- Reducing the likelihood of having a child. ${ }^{8}$

For example, in 1994 talkers were 42 percent more likely to know where to find birth control than similar nontalkers, while in 1998 talkers were 107 percent more likely to know. The most important findings are on pregnancy and STDs. In 1994, sexually experienced talkers were only 6 percent less likely to have or cause a pregnancy, while in 1998 sexually experienced talkers were 54 percent less likely to cause a pregnancy than nontalkers. Similarly, in 1998 sexually experienced talkers were 55 percent less likely to get an STD (be treated) than were nontalkers. In 1994, it appeared that youth talked to adults about STDs primarily when they suspected they had one because talkers in 1994 were more likely to get an STD than were nontalkers. It appears that adults, who now had better information on birth control and STDs, provided youth with information they better heeded, trusted and acted upon.

Overall, we can conclude that communication between a youth and a knowledgeable adult about sexuality, combined with an increase in access to contraceptives, appears to be linked to being better informed on protection and having more responsible behavior, much as the theory behind Plain Talk posits. In 1994, 33 percent of the sexually experienced youth had been pregnant or got someone pregnant. Four years later, 27 percent of the new cohort of sexually experienced neighborhood teens had been or gotten someone pregnant. However, had there been no change in the amount or quality of communication over the four-year study period, the pregnancy rate among this new cohort of teens would have been 38 percent. ${ }^{9}$ Analysis of the survey data suggests that almost all of this decrease is due to the increased effectiveness of communication. Had communication remained as ineffective as it was in 1994 (decreasing the pregnancy rate by only 6 percent compared to similar nontalkers), then the pregnancy rate would not have dropped noticeably even though more communication was taking place.

Thus far, we have examined Plain Talk's potency by examining the strengths of the paths through which the initiative was expected to work, from increasing the amount and quality of adult-youth communication about sexuality to more responsible sexual behavior. As mentioned earlier, an alternative way of determining the effect of Plain Talk would have been to collect the survey data on youth in comparable neighborhoods and compare the changes in these youth's sexual behavior to that of the youth in the Plain Talk neighborhoods. Given that neighborhoods are quite fluid in nature and that it would be unlikely that any two neighborhoods would remain comparable over the life of the initiative, this strategy was not used. 
Table 9

\begin{tabular}{|c|c|c|}
\hline \multirow[t]{2}{*}{ Population } & \multicolumn{2}{|c|}{ Year } \\
\hline & 1994 & 1998 \\
\hline Overall & $32.7 \%$ & $27.2 \%$ \\
\hline Girls & $54.5 \%$ & $33.6 \%$ ** \\
\hline Boys & $13.7 \%$ & $21.0 \%$ \\
\hline Atlanta & $39.8 \%$ & $26.2 \% \dagger$ \\
\hline New Orleans & $28.9 \%$ & $31.9 \%$ \\
\hline San Diego & $27.8 \%$ & $22.4 \%$ \\
\hline
\end{tabular}

However, to understand the general trends that were affecting sexually experienced youth (the target population) in the Plain Talk cities during the evaluation period, we examined the citywide pregnancy rates among sexually experienced youth gathered in the Youth Risk Behavior Surveillance (YRBS) Survey and the comparable pregnancy rates we observed in the Plain Talk neighborhoods in New Orleans and San Diego (see Table 10). ${ }^{10}$ [The YRBS Survey, unfortunately, does not collect data in Atlanta.] The YRBS Survey found that, among sexually experienced youth, the citywide pregnancy rates did not change over the four-year period in New Orleans for either boys or girls. In San Diego, the citywide pregnancy rate among girls appeared to decrease slightly, but it was fairly stable among the boys. In the two Plain Talk neighborhoods, the pregnancy rates among sexually experienced girls seemed to have declined. The pregnancy rates among boys were not significantly different from each other. ${ }^{11}$ Although they did not collect data in Atlanta, the CDC's national data found that pregnancy rates of sexually experienced black girls changed only slightly; it was 24 percent in 1995 and 21 percent in 1999.

On the other hand, in the Plain Talk sites the everpregnant rate among the sexually experienced girls decreased from 55 percent to 34 percent between 1994 and 1998. While these changes are encouraging, however, remember that the observed change in the pregnancy rate is a combination of general trends in each city and neighborhood, the effect of Plain Talk, and changes in the type of youth who live in these neighborhoods.

\section{Table 10}

Percent Who Were Ever Pregnant or Got Someone Pregnant Among the Sexually Experienced Youth in the Youth Risk Behavior Surveillance (YRBS) Surveys and the Plain Talk (PT) Surveys

\begin{tabular}{|c|c|c|}
\hline \multirow{2}{*}{$\begin{array}{l}\text { Population } \\
\text { and Survey }\end{array}$} & \multicolumn{2}{|c|}{ Year } \\
\hline & 1994 & 1998 \\
\hline \multicolumn{3}{|l|}{ New Orleans } \\
\hline YRBS Youth & $20 \%$ & $20 \%$ \\
\hline PT Youth & $29 \%$ & $32 \%$ \\
\hline YRBS Girls & $26 \%$ & $27 \%$ \\
\hline PT Girls & $43 \%$ & $39 \%$ \\
\hline YRBS Boys & $16 \%$ & $14 \%$ \\
\hline PT Boys & $19 \%$ & $24 \%$ \\
\hline \multicolumn{3}{|l|}{ San Diego } \\
\hline YRBS Youth & $16 \%$ & $14 \%$ \\
\hline PT Youth & $28 \%$ & $23 \%$ \\
\hline YRBS Girls & $21 \%$ & $16 \%$ \\
\hline PT Girls & $55 \%$ & $27 \% *$ \\
\hline YRBS Boys & $12 \%$ & $12 \%$ \\
\hline PT Boys & $9 \%$ & $19 \%$ \\
\hline
\end{tabular}

Although Plain Talk did not attempt to lower the number of youth who were sexually experienced, a valid question is what happened to the percentage of youth who were sexually experienced. We find the reported rate over the three sites increased between 1994 and 1998 for girls (but not boys) as shown in Table 11. In particular, it increased significantly in New Orleans and San Diego. The YRBS data from New Orleans and San Diego did not find a similar increase among girls. In both 1995 and 1999, approximately half the high school girls in New Orleans (52\% in 1994 and 51\% in 1999) had ever had sex. In San Diego, 40 percent of high school girls were sexually experienced in 1995 and 33 percent in 1999. Thus, the behavior of the girls in the Plain Talk neighborhoods may not mirror the behavior of other girls in New Orleans or San Diego. The percentage of boys who were sexually experienced did not change significantly over the period in the Plain Talk 
neighborhoods. Boys in the YRBS, on the other hand, were less likely to be sexually experienced in 1999 than in 1995. In New Orleans, the rate went from 78 percent to 70 percent and in San Diego, it went from 51 percent to 44 percent.

\section{Table 11}

Percent of Youth Who Were Sexually Experienced Among Youth in the Youth Risk Behavior Surveillance (YRBS) Surveys and the Plain Talk (PT) Surveys

\begin{tabular}{lrrr}
$\begin{array}{l}\text { Population } \\
\text { and Survey }\end{array}$ & \multicolumn{3}{c}{ Year } \\
\hline
\end{tabular}

\section{New Orleans}

$\begin{array}{lll}\text { YRBS Girls } & 52 \% & 51 \% \\ \text { PT Girls } & 44 \% & 70 \%{ }^{*} \\ \text { YRBS Boys } & 78 \% & 70 \% \\ \text { PT Boys } & 81 \% & 79 \%\end{array}$

\section{San Diego}

\section{YRBS Girls}

PT Girls

YRBS Boys

PT Boys

Atlanta

PT Girls

PT Boys
$70 \%$

$80 \%$
$40 \%$

$29 \%$

$51 \%$

$45 \%$

$38 \%$
Note: The YRBS data was collected in 1995 and 1999. For the Plain Talk numbers, we tested if 1998 rates were lower than 1994. ${ }^{*} p<.05$
Table 12

Percentage of Girls Who Were Ever Pregnant

\begin{tabular}{lcc} 
Population & \multicolumn{2}{c}{ Year } \\
& 1994 & 1998 \\
\hline All Sites & $18 \%$ & $13 \% \dagger$ \\
Atlanta & $31 \%$ & $16 \%^{*}$ \\
New Orleans & $13 \%$ & $19 \%$ \\
San Diego & $13 \%$ & $7 \%$
\end{tabular}

We tested whether 1998 rates were equal to 1994 rates. $\dagger \mathrm{p} \leq .10 \quad$ * $\mathrm{p} \leq .05$

We do not know from our research if the increase observed in the Plain Talk sites was due to teens feeling more comfortable admitting they were sexually experienced in a post-Plain Talk environment or whether the rate actually increased. The substantial evidence that information about sexuality does not increase "sexual intercourse, either by hastening the onset of intercourse, increasing the frequency of intercourse, or increasing the number of sexual partners" (Kirby, 2001), lends credibility to the hypothesis that the level of honesty changed between 1994 and 1998. However, given that we do not see a parallel reporting increase in boys, doubt remains.

On the other hand, if the observed increase among girls was due to more accurate reporting and not to an actual increase in activity, the pregnancy rate in the community should have decreased because sexually active girls were less likely to become pregnant. However, Table 11 shows that at least in New Orleans, the community-wide pregnancy rate appears to have increased, though the increase from 13 percent to 19 percent is within the survey's margin of error. The rates in Atlanta and San Diego decreased, although San Diego's decrease is in the margin of error. Given the lack of strong findings, we cannot conclusively determine what effect Plain Talk had on youth's rate of sexual activity. 


\section{Plain Talk's Implementation}

Plain Talk's ambitious strategy of changing community communication patterns, combined with improved access to contraceptives, appears to be a promising strategy for protecting adolescence. How did the sites accomplish it? Creating a new community consensus around any interest is ambitious, but it is especially challenging with such a controversial message. How were the sites able to create community consensus around preventing STDs and teen pregnancy? How effective were the community education strategies used by the sites in educating a large number of community adults? How did the sites link with other institutions? Did their efforts result in extra services for people in the community?

What follows is a brief review of the strategies the sites used during the study period (1993 to 1998) and the lessons we learned about creating and sustaining a consensus, how residents were prepared to disseminate the Plain Talk message, how the message was spread and what type of institutional changes occurred. ${ }^{12}$

\section{Building a Message and Preparing the Core Group of Residents}

The first step toward building a consensus was to bring the issues of adolescent sexuality to the attention of the community. To accomplish this goal, residents were trained to conduct surveys of community adults and youth about their attitudes, knowledge and behavior related to adolescent sexuality and contraceptive use, and to assess the contraceptive services available in the community.

The community surveying process had a profound effect in awakening and motivating residents.

Demonstrating the problems facing the communitiessuch as high rates of adolescent sexual activity, pregnancy and disease; limited adolescent knowledge about sexuality; and the unavailability and inaccessibility of health services-motivated people to participate in the initiative. Some residents who maintained their own values about the importance of abstinence were attracted to the effort and remained involved because of their surprise at the high levels of sexual activity among adolescents in their communities and their desire to help sexually active youth avoid pregnancy or STDs. 
To ensure resident input and build needed resident leadership, most core design groups consisted entirely of community residents. The original initiative design called for a core group composed of both community residents and staff from community agencies to be convened to shape the Plain Talk program and build consensus. However, at four of the five sites, it quickly became clear that with professionals at the table, residents did not feel comfortable expressing their ideas. Only in Atlanta did a small group of health care providers continue to be part of the core group. In the other sites, agency representatives organized into separate advisory committees.

\section{Developing the Plain Talk message and maintaining} the core group members' commitment to it was an intensive and ongoing process. By the end of the first year, after many sex education workshops, values clarification exercises and debate, the core group of residents in each of the five sites had crafted a program and message that promoted responsible sexual behavior and better contraceptive use among sexually active youth. But sites constantly had to attend to maintaining the consensus. Plain Talk's determination to promote protection of sexually active youth without complicating its single aim with an abstinence message was continually challenged by cultural and religious norms favoring abstinence for adolescents. Acknowledging and respecting residents' personal values about adolescent sexuality was an important step in maintaining consensus. Throughout the program, residents and staff periodically went through values clarification exercises in which they identified and acknowledged one another's personal values around adolescent sexuality. Site staff acknowledged that many residents valued abstinence, and then noted that, despite residents' personal values, the community mapping showed that many youth in their community were sexually active and therefore at risk.

Using residents to deliver the Plain Talk message was slow and labor-intensive. The Plain Talk design assumed that residents would perceive core group members, who were themselves residents, as more credible than professional agency staff. However, preparing core group members to cofacilitate workshops proved to be a labor-intensive undertaking that took far longer than expected, given the enormous amount of information to be digested. Early on, Seattle decided not to bear these training costs and hired a professional health educator. The other sites, however, continued to prepare core group members. Attrition from the groups was high and, after a year of intensive effort, none of the four sites was ready to send residents into the community as lay educators. As a result, Atlanta also hired a professional health educator and Hartford turned the workshops over to the assistant project director. San Diego and New Orleans, heavily committed to developing resident leadership, stayed the course and modified their training programs to make them shorter but more intensive. Over the next 18 months, five Promotoras in San Diego and 10 Walkers and Talkers in New Orleans completed the training and began giving workshops.

\section{Spreading the Plain Talk Word in the Community}

The Plain Talk message was spread in two ways-formally through workshops in residents' homes or the Plain Talk office, and informally through a cadre of residents who came to be known as "askable adults" and "askable parents."

Using adult residents to spread the message enhanced the sites' capacity to reach a large number of people in a relatively short time. Table 3 (page 5) shows the number of adults who attended workshops. By relying on resident facilitators, New Orleans was able to reach 800 adult residents and San Diego 1,350 adults in one year, while the two sites relying on professionals, Seattle and Altanta, reached only 300 and 125, respectively, over three years. Observations of resident-led workshops indicated that both the quality of information provided and participant interest were high. Furthermore, even though the most intensive training produced only a small group of residents with the skills required for message dissemination in formal settings, most of the sites felt they had succeeded in producing a larger cadre of "askable adults" who could present information informally in the community, function effectively as outreach workers and recruit other residents to the initiative. Data from interviews indicate that many core group members played critical roles as informed adult confidants—or "askable adults" — with youth who otherwise had no adults to confide in. 
Resident involvement substantially affected the reach and shape of the initiative in the communities. Maintaining high levels of resident involvement was a very resource-intensive endeavor but it had a profound effect on the initiative. First, resident-led discussions were much more direct. Residents appeared to be more comfortable than were professionals in broaching the difficult aspects of teenage sex with other residents. They were also more likely to talk about Plain Talk as an initiative directed toward protecting sexually active youth. And, as residents, they felt they had the responsibility and the right to challenge other community members with that message. Professional health educators, on the other hand, saw themselves as outsiders and felt less free to engage residents in discussion involving morals. Second, residents had access to people who were unknown to staff. In communities that were suspicious of outsiders, residents proved invaluable in creating and nurturing the links between the initiative and the community.

By the end of the initiative, there was agreement among all sites that workshops needed to include both factual information about adolescent sexuality and its consequences, and training in adult-youth communication. Depending on whether staff or residents drove the development of workshop curricula, they focused either on communication skills (staff) or knowledge of sexuality (residents). As experienced health educators, staff knew that providing facts does not necessarily lead to changes in behavior; and they believed that the workshops would be less controversial in some communities if communication of parents' values rather than a focus on adolescent sexuality were emphasized. Core group members, on the other hand, knew how little many adults in the community knew about contraception, anatomy and physiology, and STD symptoms, transmission and prevention. For them, having accurate information was a prerequisite to communication.

All sites eventually decided that they needed to implement workshops that covered both communication and knowledge, but developing resident facilitators' capacity to integrate the two would require significantly more training. Therefore, sites would need either to spend more resources on initial training, or pair resident facilitators with professional staff. Both have down sides: training is already a significant use of resources; residents tend to take a back seat to professionals when both are leading workshops.
"Askable parents" and "askable adults" appeared to play complementary roles in helping youth make responsible decisions about their sexual behavior. Community education targeted toward parents increased their knowledge and encouraged them to speak with youth about sexuality. Trained parents did appear more likely to speak to their children. But we found that parents had difficulty discussing sexuality, other than abstinence, with their children once they reached puberty. Their teenage children, too, indicated a reluctance to approach their parents with questions, preferring to talk to another trusted adult about sexual relationships. Further, in some cases, youth's relationships with their parents were so strained that constructive communication about sexuality was highly unlikely.

For these reasons, it appears that training should include both community adults who are parents as well as those who are not-in particular, adults who work with youth in volunteer or professional capacities. Trained residents talked to youth in the course of their jobs or volunteer work, or as neighbors, aunts or uncles, and big brothers or sisters. They spoke with the friends of their own children and with community youth they encountered in the course of the day. The adults tailored their advice to the youth's age and whether or not he or she was sexually active. Reportedly, youth seemed receptive to messages and warnings. Some communities, however, may find involving nonparental adults a violation of their views of family primacy and privacy (as it did in one of our sites).

The ease and success of Plain Talk's communitybased change strategy depended on each community's social structure. A community's capacity to develop and use strong community core groups depends to a great extent on the existing formal, institutional relationships among community members, and strong informal relationships as well. Success in recruiting and sustaining the participation of residents was greatest when site staff targeted people with large networks within the community.

Communities that had neither strong institutional infrastructures nor strong informal networks took longer to implement the community change initiative. We speculate that, in some sites, preliminary community-building might be necessary before launching an effort such as Plain Talk. Another consideration is that while the ethnically diverse communities may have had fairly strong informal or 
institutional networks within ethnic groups, there tended to be relatively few networks or social ties across ethnic lines. Implementing Plain Talk in a diverse community would require outreach staff to develop different outreach strategies for different ethnic groups, and may also require preparation of different workshops. Therefore, these types of site are likely to need more staff time to accomplish their work.

\section{Spreading the Plain Talk Word to Other Institutions}

As part of the overall effort to increase the availability and quality of adolescent reproductive health services and create a broader community consensus around the need to protect sexually active youth, Plain Talk designers knew that their message had to go beyond residents to key institutions-health care providers, schools, churches, business and government. These institutions could offer services and resources, and spread the message of protecting sexually active teens to broader audiences. Schools, for example, were good locales for workshops and informing community adults and children alike of the problems of adolescent pregnancy and STD transmission. Government and businesses were seen as potential funders. Churches, with their strong moral leadership within communities, were seen as possible vehicles for legitimizing the Plain Talk message.

The first and most obvious set of institutions approached were health care providers. At the beginning of Plain Talk, reproductive health services for youth were either lacking or limited in four of the five sites. Youth often had to travel outside their communities to find services. When clinics did exist, their hours of operation sometimes conflicted with youth's school schedules. All sites had considerable success in bringing new health services to their communities by forging strategic relationships with health care providers and sometimes successfully using residents to apply pressure on funders to support the services. Relationships with other institutions were much less developed by the end of the evaluation, partly because these efforts got underway late in the initiative and partly because the usefulness of collaborations with other institutions, such as schools, businesses and churches, were not obvious to the institutions.

In developing strategies for engaging institutions, sites learned that they had to state explicitly what a collaborative relationship with another institution could accomplish for both parties and understand the other institution's political and social contexts. In the absence of this preparation, Plain Talk sites often invited churches and businesses to participate but received no response because they did not know why they had been invited.

\section{Staffing patterns and limited resources contributed} to the relatively small gains in institutional collaboration. Staff were able to turn their attention to institutional engagement only during the last year of the project. In addition, Plain Talk staff were skilled primarily in community education and outreach, not political negotiating. In other community initiatives we have observed, institutional collaborations require the time of lead agencies' senior administrative staff who have extensive high level contacts within institutional communities. Funds were not available to engage significant executive staff time for Plain Talk, thus, few institutional links were made. 


\section{Conclusions}


The process, however, was much slower and more arduous than expected. Rather than spending one year planning and setting up the program followed by two years of spreading the word throughout the community, most sites found themselves still preparing resident trainers during the second year and only starting to implement community education and reaching out to other institutions during the third year. We found that the level of the sites' implementational achievements depended on the level of involvement of residents, the backgrounds of the targeted residents, the capacity of the lead agency and the Plain Talk staff, the degree of social cohesion within the neighborhood, and the political and institutional cultures within the cities in which the neighborhoods were located.

The fact that it takes a long time to fundamentally change societal norms should come as no surprise. For example, it took three decades for the antismoking campaigns to reduce the rate of smoking from 52 percent to 28 percent. While Plain Talk efforts reached hundreds of adults in each community and 8 percent more sexually active teens had spoken with an adult about sexuality than did at the beginning of the initiative ( $70 \%$ versus $61 \%$ ), there is much work still to be done. There are still many adults in the lives of teens who had not yet heard Plain Talk's message. Many of these adults lived in their communities but others are from other places where teens spend time-their schools and churches. The adults in the media also affect teens' ideas about behavioral norms. Thus, while the Plain Talk approach clearly is heading in the right direction, more time and continued effort will be needed to effect large changes in teen sexuality.

Finally, the Plain Talk initiative is rich in lessons about how to spark a community's interest in change and how to draw on a community's human and institutional strengths. Resident involvement is often sought by a variety of programs in an effort to improve the fit with the community and increase the likelihood of an initiative's sustainability. This evaluation is one of the first to show how involving residents can dramatically change an initiative's shape and implementation. 


\section{Afterword}

While Plain Talk's demonstration phase ended in 1999, the Plain Talk story continues to evolve on many different fronts.

First, and perhaps most important, Plain Talk activities continue in all of the original sites. In each of the Plain Talk communities, sites are using public and private dollars to continue the most successful components of their work.

- In Atlanta, the Center for Black Women's Wellness received a multi-year grant from the Department of Health and Human Services to reduce infant mortality by engaging residents in a neighborhood-based prevention strategy that targets teens.

- The Hartford Action Plan on Infant Health is leading a citywide campaign to improve access for adolescents to reproductive health services. The campaign has won support from the mayor, school superintendent and the health department director. Most recently, these officials joined together to allow school-based health centers to distribute information about contraceptives and STDs.

- In New Orleans, the Plain Talk model for Walkers and Talkers has been adapted to enroll more than 800 families in Medicaid. The Logan Heights Family Health Center in San Diego has received a state grant to increase the involvement of men in Plain Talk. Furthermore, the Health Center has received enough federal funds to support 30 additional hours of clinical adolescent reproductive health services.

- And in Seattle, the Plain Talk neighborhoods and partners are continuing their community change process through involvement in the planning and implementation of an initiative with even broader goals, Making Connections, that is aimed at improving the odds for families in tough neighborhoods.
The Plain Talk initiative is now being replicated in additional sites, largely through support from state and federal government resources. In Chicago, The Annie E. Casey Foundation is partnering with the Centers for Disease Control and the University of Illinois to replicate Plain Talk as part of the CDC's national teen pregnancy prevention demonstration project. More recently, in Michigan, the state decided to replicate Plain Talk in Wayne County using bonus funds from the federal government awarded for significantly reducing out-of-wedlock births.

Furthermore, as part of its replication and dissemination strategy, the Foundation and the first cohort of Plain Talk sites are providing workshops and peer-topeer technical assistance in such key venues as the National Organization on Adolescent Parents and Pregnancy Prevention's annual conference. The Foundation and the sites have also co-designed training resources. By far the most accessible and indemand tool developed is the Plain Talk Starter Kit, a practical guide to community-based programs seeking to reduce teen pregnancy, STDs and HIV/AIDS.

Debra Delgado

Senior Program Officer

The Annie E. Casey Foundation 


\section{Endnotes}

1. Three reports detail the Plain Talk evaluation findings: The Plain Talk Planning Year (Kotloff et al.); Plain Talk: Addressing Adolescent Sexuality Through A Community Initiative (Walker and Kotloff); and The Effect of Plain Talk on Youth (Grossman and Pepper).

2. A sixth site, Indianapolis, began the demonstration but, after the first year of the project, the lead agency concluded that it could not commit to the Plain Talk message of protecting sexually active youth and withdrew from the demonstration.

3. To target evaluation resources most effectively, surveys were conducted in three of the five communities on the assumption that surveying three communities would be sufficient to see if changes had occurred, while reserving resources for other parts of the evaluation. The three that were chosen started their programs first.

For both the baseline and follow-up surveys, a random set of youth ages 12 to 18 living in three communities in Atlanta, New Orleans and San Diego were interviewed in person in their homes. The baseline surveys were conducted in the Fall of 1994 in New Orleans and San Diego, and in the Spring of 1995 in Atlanta. (Atlanta's program started six months later than did New Orleans' and San Diego's.) The follow-up surveys were conducted in Fall 1998 in Atlanta, Fall 1998 in San Diego and Spring 1998 in New Orleans. Thus, in Atlanta, the follow-up survey was conducted approximately three years after Plain Talk started; while in San Diego and New Orleans, the follow-up was approximately four years from start-up. In each round, only one teen per household was interviewed.

4. While these developments are good news, the rates of pregnancy among teens is still high by European standards.

5. There is a 15 percent chance that New Orleans' apparent increase is spurious.

6. Table 8 presents the estimated odds ratios resulting from a logit analysis of pooled 1994 and 1998 data controlling for the year, youth's gender, age, race, birthplace, religion, frequency of attendance at religious services, presence of siblings with children prior to age 18 and city of residence, as well as our variables of interest: whether the youth had spoken with an adult about birth control in the prior year and 1998 site-specific effects.

7. The numbers in Figure 2 are the estimated effect of communication in 1998 derived from multivariate analyses of the pooled 1994 and 1998 data. All the analyses include the following independent variables: two variables for whether the youth had spoken to an adult about pregnancy, STDs or birth control over the last yearone for 1994 and one for 1998; site dummies for 1994 and 1998, the variable in Table 4-age, race, gender, immigrant status, and religiosity variables. For Using Birth Control at Last Sex, Creating a Pregnancy, Being Tested for an STD, and Being Treated for an STD, we also include measures of whether the youth knew where to find birth control and how comfortable they were with condoms. The results from the statistical analyses are available from $\mathrm{P} / \mathrm{PV}$.
8. Although in only one case-being treated for an STD-were the 1998 and 1994 coefficients statistically different from each other

9. This pregnancy rate was predicted using our statistical model. We set the proportion of youth who talked to adult at the 1994 level, used the 1994 coefficients but used the 1998 level for all other youth characteristics (such as religion, frequency of religious attendance, etc.).

10. The Youth Risk Behavior Surveillance (YRBS) Survey is collected by the Centers for Disease Control every other year. It gathers information from a nationally representative sample of high school students. Fortunately, two of the cities in the survey are New Orleans and San Diego. We present the findings for 1995 and 1999, the two closest years to the Plain Talk survey time frame.

11. While only the decline in San Diego is statistically significant by itself, if the samples in both cities are combined, there is a statistically significant decline in pregnancy among the sexually experienced girls (from $49 \%$ to $34 \%, \mathrm{p}=.06$ ) and no significant change in the boys (from $14 \%$ to $21 \%, \mathrm{p}=.18$ ).

12. For a fuller discussion, see Walker and Kotloff, 1999. 


\section{References}

Berne, Linda, and Barbara Huberman

1999 European Approaches to Adolescent Sexual Behavior and Responsibility. Washington, D.C.: Advocates for Youth.

Brown, S.S., and L. Eisenberg (eds.)

1995 The Best Intentions: Unintended Pregnancy and the Well-Being of Children and Families. Washington, D.C.: National Academy Press.

Figueroa, Darryl, and Nyjeri Redus

1998 "Differing European/US Approaches to Teen Sex Show Surprising Results," Washington, D.C.: Advocates for Youth. Available on their website at http://www.advocatesforyouth.org /publicaffairs/communications/ESTRETUR.htm.

\section{Grossman, Jean, and Sarah Pepper}

1999 "The Effect of Plain Talk on Youth." Working paper. Philadelphia: Public/Private Ventures.

Henshaw, Stanley K.

1999 Special Report: U.S. Teenage Pregnancy Statistics, with Comparative Statistics for Women Aged 20-24. New York: Alan Guttmacher Institute.

\section{Kirby, Douglas}

2001 Emerging Answers: Research Findings on Programs to Reduce Teen Pregnancy. Washington, D.C.: National Campaign to Prevent Teen Pregnancy.

Kirby, Douglas

1999 "Reducing Adolescent Pregnancy: Approaches that Work." Contemporary Pediatric, 16(1).

\section{Kirby, Douglas}

1997 No Easy Answers: Research Findings on Programs to Reduce Teen Pregnancy. Washington, D.C.: National Campaign to Prevent Teen Pregnancy. Available on their website at http://www.teenpregnancy.org/fmnoeasy.htm.
Kotloff, Lauren, Phoebe Roaf, and Michelle Alberti Gambone 1999 The Plain Talk Planning Year. Philadelphia: Public/Private Ventures.

\section{Raymond, M., and S.B. Silverberg}

1998 “'But She's My Mom!': A Narrative Analysis of MotherDaughter Sexuality Communication.” Presented at the Seventh Biennial Meeting of the Society for Research on Adolescence, San Diego, California.

Rosenthal, D.A., and S.S. Feldman

1998 "The Importance of Importance: The Differentiated Nature of Parent-Adolescent Communication about Sexuality.” Presented at the Seventh Biennial Meeting of the Society for Research on Adolescence, San Diego, California.

Santelli, John, Laura Duberstein Lindberg, Joyce Abma, Clea Sucoof McNeely, and Michael Resnick

2000 "Adolescently Sexual Behavior: Estimates and Trends from Four National Representative Surveys.” Family Planning Perspectives, Vol. 32:4, July/August.

Singh, Susheela, and Jacqueline Darroch

2000 "Adolescent Pregnancy and Childrearing: Levels and Trends in Developed Countries." Family Planning Perspectives, Vol. 32:1, Jan/Feb, pp.14-23.

Walker, Karen, and Lauren Kotloff

1999 Plain Talk: Addressing Adolescent Sexuality Through A Community Initiative. Philadelphia: Public/Private Ventures. 


\section{PPV}

Public/Private Ventures

2000 Market Street

Suite 600

Philadelphia, PA 19103

Tel: $\quad 215 / 557-4400$

Fax: $215 / 557-4469$

Url: http://www.ppv.org

December 2001 